\title{
ORIGINALIDAD DE LA METAFÍSICA CUSANA: LA NEGACIÓN EN CUANTO PRINCIPIO PRIMERO'
}

\author{
ORIGINALITY OF CUSANUS'S METAPHYSICS: \\ NEGATION AS FIRST PRINCIPLE
}

\author{
JORGE MARIO MACHETTA* \\ Dr. en Teología \\ Universidad del Salvador - Buenos Aires - Argentina
}

Artículo recibido el 30 de julio de 2020; aceptado el o7 de noviembre de 2020.

*jorgemachetta@yahoo.com.ar

Cómo citar este artículo:

J. M. Machetta. (2020). "Originidad de la metafísica cusana: La negación en cuanto principio primero" en Palabra y Razón. Revista de Teología, Filosofía y Ciencias de la Religión. № I8 Diciembre 2020, pp 39-68 https://doi.org/IO.29035/pyr.I8.39

\footnotetext{
I La presente investigación reelabora y profundiza nuestras anteriores investigaciones: J. M. MACHETTA, "La negación en cuanto principio primero de la metafísica cusana" en El problema del conocimiento en Nicolás de Cusa: Genealogía y proyección, J. M. MACHETTA, C. D' AMICO, (eds.) Biblos: Buenos Aires, 2005, pp. I65-I82; J. M. MACHETTA, "Los nombres de Dios y la novedad de la metafísica cusana" en A quaestao da Deus na Historia da Filosofia, M. L. XAVIER (coord.), Zéfiro:Portugal, 2008, pp. 527-546; J. M. MACHETTA, "Tradición y originalidad: La metafísica de Nicolás de Cusa", Revista de la Facultad de Filosofía de la Universidad de Morón, Vol. XV, n I7/I8 (20I2), pp. IOI-I24.
} 


\title{
RESUMEN
}

Nuestra exposición se desarrollará en tres momentos: En el primero presentaremos la originalidad del pensamiento de Nicolás de Cusa (I4OI-I464) expresado en su fórmula "acerca de la docta ignorancia", es decir, sobre el saber del no saber en cuanto es el recurso insustituible para expresar la absoluta perfección del principio de todo: Dios. En un segundo momento mostraremos como dicha originalidad se diferencia de la tradición escolástica que elaboraran tanto Alberto Magno como Tomás de Aquino apelando a la metafísica del ser propuesta por Aristóteles. En un tercer momento expondremos textos cusanos correspondientes a sus obras posteriores en los cuales se reelabora y profundiza temáticamente el principio de la negación. Nuestra aspiración es que este recorrido realizado a través de los textos nos brinde una imagen completa de la profunda originalidad del pensamiento cusano.

Palabras claves: Principio / negación / afirmación / proporción / coincidencia

\begin{abstract}
Our paper will be developed in three moments. First, we will present the originality of Nicholas de Cusa's thought (I4OI-I464) expressed in his formula "about learned ignorance", that is to say, on the knowledge of not knowing as it is the irreplaceable resource to express the absolute perfection of the beginning of everything: God. In a second moment we will show how this originality differs from the scholastic tradition elaborated by both Albertus Magnus and Thomas of Aquinas, appealing to the metaphysics of being proposed by Aristotle.Thirdly, we will present passages from Cusanus's later works, in which the principle of negation is reelaborated and thematically deepened. Our aspiration is that this path through Cusanus's texts provides us with a complete image of the deep originality of Cusanus's thought.
\end{abstract}

Keywords: Principle / negation / affirmation / proportion / coincidence 


\section{I) Introducción}

Con esta exposición nos proponemos poner de manifiesto el rol y la exclusividad que Nicolás de Cusa asigna a la negación en cuanto recurso insustituible para expresar no solo la perfección absoluta de Dios, sino también su carácter de principio y fundamento de toda realidad. Nos interesa el giro copernicano que su metafísica significó frente a la solidez ontológica de la tradición escolástica expresada en Alberto Magno y Tomás de Aquino.

Abordaremos en primer lugar la "novedad" cusana fundada en la interpretación del apetito de saber que nutre la inquisición filosófica, es decir la docta ignorancia en cuanto es la única y exclusiva condición del posible acceso al principio absoluto. En un segundo momento nos interesa presentar la concepción escolástica de la metafísica tal como la exhiben Alberto Magno y Tomás de Aquino a fin de resaltar su diferencia con la novedad cusana. Y en un tercer momento consideraremos textos cusanos seleccionados de sus obras posteriores en los cuales se reelabora y profundiza temáticamente el principio de la negación. Consideramos que de esta manera podremos ofrecer una visión completa de la innovación cusana de la metafísica.

\section{2) La novedad cusana}

Nicolás de Cusa, I4OI-I464, es una figura descollante del siglo XV, época particularmente afectada por profundas crisis religiosas, doctrinarias y políticas $^{2}$. En ella la decadencia de las formas de la vida medieval en los ámbitos no solo políticos sino también especulativos y en especial a raíz del incipiente renacimiento, generan la aspiración a un cambio. En este contexto histórico Nicolás ha puesto de manifiesto no sólo su competencia para la política eclesiástica sino, muy particularmente, su profunda y original concepción intelectual.

Podemos descubrir esta tradición en el primer sermón que Nicolás pronuncia en I430 en Coblenza, cuya primera parte está dedicada a la cuestión de "los nombres de Dios”. “¿Quién puede atreverse a explicar el

2 Dos obras se esfuerzan por proponer el singular perfil de Nicolás de Cusa en su tiempo: G. SANTINELLO Introduzione à Nicolò Cusano con aggiornamento bibliografico. Bari: Roma, I987; K. FLASCH, Nikolaus von Kues Geschichte einer Entwicklung, Klostermann Vittorio GmbH: Frankfurt a. Main, 2008.

3 Las obras cusanas se citan de acuerdo a la edición crítica, donde h: NICOLAI DE CUSA, Opera Omnia, Iussu et Auctoritate Academiae Litterarum Heidelbergensis, Leipzig, 1932 ss., indicando en cada caso el volumen y número de parágrafo y página (si es el caso). NICOLÁS DE CUSA, 
nombre tan infinito, inmenso e inconcebible de Dios?"4, se pregunta en el prólogo de su predicación. Más aún, para describir esta distancia entre Dios y el hombre apela al tradicional símil del ave vespertina incapaz de ver la luz. ${ }^{5}$ En consecuencia no podrá sorprendernos la conclusión que enuncia más adelante: "es manifiesto que el intelecto humano no solamente es débil con su propia visión para la percepción de esta luz excelente, sino que permanece, por su propia naturaleza, totalmente ciego" .

Pareciera, entonces, que la única conclusión aceptable ha de ser que sólo podríamos acceder a Dios a través del silencio y la adoración. Ciertamente Nicolás nunca renunció a este principio de la inefabilidad divina. Desde muy temprano había descubierto los textos del Pseudo Dionisio Areopagita ${ }^{7}$. En cuanto "sumo bien" Dios es la perfección misma ${ }^{8}$. "Dios es nombrado con diversas voces humanas en las varias lenguas de las naciones, pero su nombre es único, inefable e incógnito"?. Sólo hay un nombre, que por provenir directamente de Dios se sustrae a nuestra comprensión humana: es el tetragramaton de la Biblia hebrea..$^{10}$ De todas formas reconoce y menciona, no solo respecto de la tradición bíblica sino también de todos los pueblos una gran variedad de denominaciones de Dios. Su conclusión es que precisamente tal variedad pone de manifiesto la inefabilidad de Dios. Sin embargo Nicolás no avanza aquí en su reflexión y deja la antinomia sin resolver: por una parte en virtud de su inefabilidad Dios es sobre todo nombre y sobre todo intelecto creado, por otra, en cambio, los hombres nombran a Dios y le atribuyen diversas perfecciones, y ello es una manera de reconocer su grandeza. Pero estos

\footnotetext{
Sermo I (h XVI/I): I In principio erat Verbum, pp.I-I9.

4 NICOLÁS DE CUSA, Sermo I, (h XVI/I): "Quis enim tam infiniti , inmensi, inconcetibilique summi dei nomen audet explicare?"

5 Se trata de una comparación que todos los escolásticos reproducen y que ha sido tomada de ARISTÓTELES Metaphyc. II, I, a Ioo3 b 9-II; ALBERTO MAGNO Metaphys. II I, 2 Opera Omnia, XVI, B. GEYER (ed.), p. 92.

6 NICOLÁS DE CUSA, Sermo I (h XVI/I), p. 2: "manifestum est humanum intellectum ad huius tam excellentis lucis perceptionem non modo sua intrinseca visione debilem, verum penitus coecum ex sua natura remanere".

7 Ver por ejemplo el estudio preliminar de L. BAUR en Cusanus Texte III Marginalien Nikolaus Cusanus und Ps.Dionysius im Lichte der Zitate und Randbemerkungen des Cusanus, Heidelberg I94I, pp. 9-I8.

8 NICOLÁS DE CUSA, Sermo I, p. 3: "Deus quia omnis boni et perfectionis, virtutis et veritatis origo a nullo dependens et a quo omnia, ipsum summum bonum esse necesse est".

9 NICOLÁS DE CUSA, Sermo I, p. 4 lin.3: "Nominatur humanis diversis vocibus,diversis linguis diversarum nationum, licet nomen suum sit unicum,summum,infinitum, ineffabile et incognitumt".

Io NICOLÁS DE CUSA, Sermo I, p. 5 lin.I6: "Unum tamen sanctissimum cuius interpretationem humanus intellectus apprehendere nequit a Deo datum quod est tetragrammaton, id est quattuor litterarum, est inefabile id est per intellectum inconceptibile".
} 
hechos no aclaran las preguntas: ¿Qué es, entonces, lo que legitima tales usos? ¿Cuál es el valor de dichos nombres? Evidentemente si el nombre proporciona, de alguna manera, un cierto conocimiento respecto de lo nombrado, ello sólo puede provenir de nuestra capacidad de conocer, sin embargo aceptar la grandeza infinita de Dios implica reconocer su inaccesibilidad. ¿Será posible encontrar una respuesta a este dilema?

A nuestro entender, es ésta la cuestión que intenta resolver Nicolás con su obra Acerca de la docta ignorancia, escrita en I440. En efecto, en el epílogo de la obra confiesa que ha sido precisamente el "don del Padre de las luces" lo que le permitió: que "abrazara lo incomprensible incomprensiblemente en la docta ignorancia por medio de la superación de las verdades incorruptibles que pueden saberse humanamente" Consciente de sus propias limitaciones, pero mucho más de "la audacia con que él ha sido llevado para tratar acerca de la docta ignorancia" fórmula paradójica que resume la dificultad de la tarea que se propone: brindar por una parte un saber, fruto de un ejercicio intelectual, que es calificado, a la vez, como ignorante.

Nicolás avanzará gradualmente a través de este nuevo camino. Apela, en primer lugar al clásico tropo de la "admiración, a causa de la cual se filosofa"13, por cuanto es el estímulo por el cual el intelecto "se perfecciona con la dedicación a la verdad"I4. En efecto, consecuente al ejercicio del conocimiento "el apetito no ha de resultar inútil" sino por el contrario se trata de que "puede alcanzar el sosiego en lo amado por la tendencia de la propia naturaleza" (n.2). Por ello mismo "el sano y libre intelecto conoce lo verdadero" (ibid.). Sin embargo, tan rotundas afirmaciones no parecen poder conciliarse con el título propuesto a este primer capítulo introductorio: "En qué sentido saber es ignorar". Por tanto, es importante encontrar el hilo conductor de la argumentación cusana que él mismo califica como "máxima doctrina de la ignorancia" (n.5). La primera parte de su análisis la dedica Nicolás a la investigación del alcance y sentido del ejercicio del conocimiento humano, luego establecerá, en el capítulo tercero, la relación de dicho conocimiento con la verdad definida como precisión. En ambos análisis se harán

II NICOLÁS DE CUSA, , De docta Ignorantia, III (h. I, n. 263): "ad hoc ductus sum, ut incomprehensibilia incomprehensibiliter amplecterer in docta ignorantia per transcensum veritatum incorruptibilium humaniter scibilium".

I2 NICOLÁS DE CUSA, Acerca de la Docta ignorancia, Libro I: lo máximo absoluto, J. M. MACHETTA, C. D'AMICO, Biblos: Buenos Aires, 2003, n. I. En el texto nos referiremos a esta edición mencionando el número correspondiente al texto citado.

I3 NICOLÁS DE CUSA, De doc. ign., n. I.

I4 NICOLÁS DE CUSA, De doc. ign., n. I. 
patentes dos aspectos fundamentales. Por un lado, la consideración de la imperfección e insuficiencia de dicho ejercicio cognoscitivo, tanto en la metodología adoptada: el recurso a la proporción, como respecto del resultado obtenido en relación con la verdad. Y particularmente desde ambos requerimientos de nuestro modo de conocer se pregunta por lo infinito o máximo. Es en este punto donde surge la originalidad del pensamiento cusano dado que la insuficiencia y los límites que todas las experiencias cognoscitivas ponen de manifiesto que lejos de constituir una barrera para el apetito de verdad que guía a la inteligencia, la habrá de conducir, y ésta será la tesis fundamental de Nicolás, a un nivel de superación expresado por medio de esta paradójica sentencia: "Y por tanto será tanto más docto, cuanto se sepa a sí mismo más ignorante" (n.4).

Comienza con la descripción del conocimiento como proceso que va desde lo más conocido a lo que todavía no lo es, de modo que el ejercicio de conocer implique progresar en el saber. Ello se obtendrá si puede establecerse entre lo conocido, y lo no conocido lo que posibilite una comparación o proporción. Esto implica dos exigencias. Primero que se dé una cierta igualdad común, base de toda relación posible, pero además que pueda advertirse una cierta diferenciación entre ambos, pues de lo contrario estaríamos ante la pura identidad. Nicolás llama a esto "proporción comparativa"15 o bien simplemente "proporción"16.

Ahora bien, "la proporción no puede ser entendida sin el número. Por lo tanto, el número incluye todas las cosas proporcionables" ${ }^{17}$. La misma doctrina será ampliamente desarrollada en el libro segundo, a propósito del conocimiento del universo. Allí afirma: "El número proviene de nuestra mente por esto: que entendemos muchas cosas singularmente en relación a lo uno común"18. El número proviene de la unidad y concluye en la diversidad. Por lo cual lo diverso, es decir aquello todavía no conocido, pero que exhibe una nota común, lleva en sí mismo lo que lo vincula a la unidad y aunque el número no es lo mismo que la unidad, sin embargo, no puede ser pensado sin entrar en relación con ella. Por ello mismo advierte: "Suprimiendo el número cesan la distinción, el orden, la proporción, la armonía de las cosas y además la

I5 NICOLÁS DE CUSA, De doc. ign., n. 2.

I6 NICOLÁS DE CUSA, De doc. ign., n. 2.

I7 NICOLÁS DE CUSA, De doc. ign., n. 3.

I8 NICOLÁS DE CUSA, Acerca de la docta ignorancia, Libro II: Lo máximo contracto o universo (edición bilingüe) J. M. MACHETTA, C. D'AMICO y S. MANZO (eds.), Buenos Aires 2004. Citamos el número del párrafo: $\mathrm{n}$ Io8. 
misma pluralidad de los entes"19.

De todas formas, estas afirmaciones podrían dar pie a una objeción: la primacía que se otorga a la proporción y por consiguiente al número ¿no implica, acaso, el peligro de reducir al ámbito de lo mensurable y cuantitativo el ejercicio del conocimiento dejando en un cono de sombra toda otra realidad ajena a los parámetros de la mensura? Más aún podríamos preguntarnos si esta preferencia por el vocabulario afín a las matemáticas no implica de suyo establecer una barrera que impida alcanzar a Dios por la vía del conocimiento sobre todo cuando nos encontramos ante la enfática formulación cusana de que "lo infinito en cuanto infinito, puesto que escapa a toda proporción es desconocido"20. Por tanto, si el conocimiento se resuelve a través de la proporción, el abismo que separa la finitud de la infinitud imposibilita el punto común que toda proporción exige. En consecuencia, será necesario reflexionar más profundamente no sólo acerca del concepto mismo de infinito sino también replantear nuestras posibilidades cognoscitivas. Respecto de la infinitud se ha de tener en cuenta la modalidad que adquiere cuando es aplicada al número por cuanto podemos pensarlo en su progresión ascendente, o bien en su regresión, un proceso sin término por cuanto siempre será posible añadir o bien sustraer un número más o menos, y en ese sentido no habrá límite sino "progressio ad infinitum". Nicolás advierte explícitamente que el resultado de tal especulación no hace sino subrayar su potencialidad. Aún en la hipótesis, nos dice, de arribar al "máximo número" embargo a lo máximo mayor a lo cual no puede ser, porque tal habría de ser infinito, de donde concluye "Por lo cual es claro que el ascenso del número es finito en acto y que tal número estará en potencia para otro" ${ }^{22}$, es decir, no será un número mayor al cual no pueda ser, lo que imposibilita que se lo considere en sí, es decir, en acto, infinito. Precisamente Nicolás retomará este planteo para poner de manifiesto la posibilidad para pensar la coincidencia de los opuestos. Pero a ello nos referiremos luego.

Se hace necesario, entonces, analizar el concepto mismo de maximidad a fin de poner de manifiesto cuál deba ser la infinitud

I9 NICOLÁS DE CUSA, Acerca de la docta ignorancia I, cap. V, n I3. La cuestión del número en relación con el conocimiento ha sido ampliamente tratada por Nicolás en su obra De coniecturis (h. III), I, cap.2.

20 NICOLÁS DE CUSA, De doc. ign., n. 3.

2I NICOLÁS DE CUSA, De doc. ign., n. I3.

22 NICOLÁS DE CUSA, De doc. ign., n. I3. 
predicable de Dios. "Ahora bien, nos dice, llamo máximo a esto: lo que nada mayor que ello pueda ser" ${ }^{23}$, con lo que incorporaa su especulación la tradicional formulación anselmiana, y en seguida añade: "la abundancia que ello implica sólo puede convenir a lo uno" ${ }^{24}$. En consecuencia, maximidad, unidad y entidad son lo mismo, por tanto nada se opone a lo máximo sino que todo es en la unidad o maximidad. Insiste en caracterizar dicho máximo como absoluto, es decir, desvinculado, o bien a nada vinculado, pues nada hay de lo cual dependa ni tampoco nada se le contrapone. Y para que no surja la sospecha de que estamos ante la utilización de significaciones ligadas a nuestras limitaciones nos advierte: "conviene, empero, a quien quiera alcanzar el sentido, más bien elevar el entendimiento por sobre la fuerza de las palabras, que insistir en las propiedades de los vocablos, los cuales no pueden ser adaptados propiamente a misterios tan elevados" 25 .

Desde este horizonte de la maximidad Nicolás enuncia el sentido del camino iniciado en la consideración del número. Atento a la necesidad de superar una infinitud que pueda quedar comprometida con este recurso al número nos dice: "Empero, no puede la unidad ser número, porque el número que admite excedente, de ninguna manera puede ser en cuanto tal ni mínimo ni máximo, pero (la unidad) es principio de todo número porque es lo mínimo, y es el fin de todo número porque es lo máximo. Por lo tanto la absoluta unidad a la cual nada se opone, es la misma maximidad absoluta" ${ }^{26}$. Profunda distinción que preserva la absolutez de la unidad sin que por ello se desconozca su imprescindible presencia, en cuanto principio y fin para todo lo que de ella provenga.

Además, aflora aquí la original intuición fundamental cusana: la coincidencia de los opuestos. De ella trataremos enseguida, pero retengamos antes la conclusión que Nicolás propone sobre las consideraciones propuestas: "Advierte, nos dice, que hemos sido llevados por el número a esto: que podamos entender que a Dios innombrable conviene como lo más cercano la unidad absoluta y que Dios es de tal manera uno que es en acto todo aquello que es posible. Por lo mismo la unidad misma no recibe ni más ni menos, ni tampoco es multiplicable"27.

Luego de todas las precisiones y diferencias acerca del significado

\footnotetext{
23 NICOLÁS DE CUSA, De doc. ign., n. 15. 24 NICOLÁS DE CUSA, De doc. ign., n. 15. 25 NICOLÁS DE CUSA, De doc. ign., n. 8. 26 NICOLÁS DE CUSA, De doc. ign., n. I4. 27 NICOLÁS DE CUSA, De doc. ign., n. I4.
} 
y aplicabilidad del vocabulario utilizado, y sobretodo, sin renunciar a la inefabilidad de Dios, propone un término: la unidad absoluta como lo más cercano, es decir, más próximo a lo que se pueda decir acerca de Dios, aunque ello no se identifique absolutamente con Él, y a la vez, que deba ser lo más contrapuesto a todo cuanto está vinculado con la progresión proporcional, la cual, dada su finitud, dista infinitamente de Él.

¿Qué es lo que ha permitido y legitimado esta superación de la antinomiafinito-infinito que en principio parecía paralizaro imposibilitar todo posible acceso a Dios? La respuesta nos la proporciona la genial intuición cusana acerca de la coincidencia de los opuestos. Tratemos entonces de explicitar, aunque sea sintéticamente, este fundamental concepto. Nicolás acaba de referirse a un vocablo como "el más cercano" a lo que Dios es. Ahora bien, inmediatamente considera imprescindible encuadrar dicha afirmación dentro del principio de la inefabilidad de Dios. El resultado lo expresa con esta paradójica fórmula: "No alcanzamos lo máximo de otra manera que incomprensiblemente, puesto que la verdad es infinita" 28 .

En primer lugar ¿Qué significa, o al menos, implica aquí "alcanzar"? ¿A qué se refiere con el adverbio "incomprensiblemente"? Desde un principio el término alcanzar aparece ligado al resultado de un esfuerzo o de un ejercicio de conocimiento. Es lograr aquello a lo que nuestro apetito de saber nos impulsa. Por eso mismo en los textos anteriores trató del alcance del entendimiento y lo explicó valiéndose de la proporción comparativa. Sin embargo, está fuera de duda que tal procedimiento es inadecuado cuando se trata de Dios. Por tanto, alcanzar, no puede aquí significar comprender proporcionalmente: lo cual es el ejercicio propio de la razón humana. Más aún, especialmente puso de manifiesto que, aún en el conocimiento proporcional nunca se llega a conocer perfectamente el ser de lo conocido. En ese sentido Nicolás ha señalado ya desde un principio que la precisión de la verdad es inalcanzable para todo entendimiento finito y a ello ha destinado el capítulo tercero del presente libro. Por tanto si legítimamente se puede decir que "alcanzamos", será para señalar aquello que legítimamente se puede decir de Dios, aunque sólo se obtenga "incomprensiblemente", es decir, dejando de lado el recurso a la proporción. Hay entonces un profundo misterio respecto del ser de todas las cosas. Particularmente es necesario despojar dicho alcance de toda afirmación o negación que

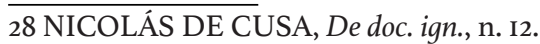


provenga de nuestro modo proporcional de conocer. En este punto Nicolás recuerda, una vez más, la implicancia de la maximidad. Dado que lo máximo "no es de la naturaleza de aquello que admite excedente y exceso", es decir que se diferencia de lo que puede ser gradualmente diverso, "está por sobre todo aquello que puede ser concebido por nosotros", por lo tanto se ubica por sobre cuanto nuestro modo de conocer puede pensar y en virtud de ello agrega la siguiente conclusión: "en consecuencia la máxima igualdad, que de ninguna manera es distinta o diversa, excede todo entendimiento" ${ }^{29}$ o sea que consecuentemente no será posible comprender intelectualmente qué sea la máxima igualdad. Desde estos supuestos enuncia Nicolás este principio: "lo absolutamente máximo es todo aquello que puede ser y por ende totalmente en acto"30. Con lo cual, apelando ya al usual vocabulario escolástico para referirse a la condición ontológica de los seres recurre a la fórmula "en acto", contrapuesta ciertamente a la locución "en potencia". No es, por lo tanto, ni más grande, o sea máximo, ni más pequeño, o sea mínimo porque nada se agrega o sustrae a ello. Es, entonces, simplemente "todo cuanto puede ser" ${ }^{31}$. Establecido este fundamento nos propone la sorprendente consecuencia: "por lo tanto es manifiesto que lo mínimo coincide con lo máximo"32. Es cierto que ningún escolástico puede renunciar, sea cual fuere la fundamentación que sostenga su concepción acerca de Dios, a la omnímoda perfección de Dios. Pero Nicolás no accede a esta conclusión para unirse meramente al coro de los autores escolásticos. No en vano ha recorrido un prolijo itinerario sopesando minuciosamente cada término y estando muy atento a nuestro ejercicio cognoscitivo. Lo que Nicolás destaca es que no podemos proyectar sobre la maximidad propia de Dios nuestras determinaciones acerca de la maximidad, porque ello significaría ponerle un límite a la infinitud. De ahí que no es posible distinguir ni menos contraponer, en este caso, máximo y mínimo porque tanto uno como otro, por cuanto no aceptan la posibilidad de ser más o menos que lo que son, es decir aquello mayor o bien menor al cual no hay, son lo mismo, es decir, coinciden.

Para ilustrar nuestra perplejidad propone Nicolás inmediatamente un símil: "Esto resultará más claro si contraes lo máximo y lo mínimo a la cantidad. Pues la máxima cantidad es máximamente grande, la mínima cantidad es máximamente pequeña. En consecuencia, desvincula de la cantidad lo máximo y lo mínimo sustrayendo intelectualmente lo

29 NICOLÁS DE CUSA, De doc. ign., n. II. 30 NICOLÁS DE CUSA, De doc. ign., n. II. 3I NICOLÁS DE CUSA, De doc. ign., n. II. 32 NICOLÁS DE CUSA, De doc. ign., n. II. 
grande y lo pequeño. Así ves claramente que lo máximo y lo mínimo coinciden. Por lo tanto, la cantidad absoluta no es más máxima que mínima porque en ella lo mínimo es lo máximo coincidentemente" 33 es decir, si la cantidad no es sino cantidad, o sea cantidad absoluta, es igualmente máxima o mínima, lo que no agrega ni sustrae nada a lo que ella es.

Pero más allá de estas aclaraciones adquiere especial importancia la aplicación de esta doctrina respecto de las afirmaciones o negaciones que se predican acerca de Dios. En efecto, como dice Nicolás, en virtud de la coincidencia, lo absolutamente máximo "está sobre toda afirmación y de la misma manera también sobre toda negación". Por ello mismo, "todo aquello que se concibe que es, no es más es que no-es. Y todo aquello que se concibe que no es, no es más no es que es"34. Es decir, al considerar los términos en cuanto a su absolutez, máxima o mínima, no acepta oposición alguna: tanto en cuanto a lo que afirma cuanto respecta a lo que niega. De este modo Nicolás renuncia explícitamente al principio de la lógica clásica, como constataremos luego al tratar del pensamiento escolástico que sostiene que "toda negación se funda en una afirmación".

El ejemplo que aduce en este sentido es elocuente: "No es, pues, decir otra cosa: Dios que es la misma maximidad absoluta es luz, que Dios de tal manera es máximamente luz que es mínimamente luz". A qué se debe ello lo explica enseguida: "Esto es así porque trasciende todo nuestro intelecto que no puede combinar en su principio los contradictorios por vía de la razón. Por tanto, sobre todo discurso de la razón vemos incomprensiblemente la absoluta maximidad que es infinita" ${ }^{35}$. Nuevamente es la cabal significación de infinito la que marca la diferencia.

Por lo tanto, si por una parte la inefabilidad de Dios supera todo nuestro discurso intelectual estructurado en torno a afirmaciones y negaciones que no hacen sino confirmar la limitación del alcance de nuestro conocimiento, entonces al enunciar aquí explícitamente el término: "vemos" presenta un modo cognoscitivo que no se resuelve discursivamente, aunque no deje de considerársele, como lo dirá en posteriores escritos, como conocimiento peculiar. Por otra parte, a fin de evitar que este proceso se entienda como el de la elevación progresiva

33 NICOLÁS DE CUSA, De doc. ign., n. I2.

34 NICOLÂS DE CUSA, De doc. ign., n. I2.

35 NICOLÁS DE CUSA, De doc. ign., n. I2.

Palabra y Razón ISSN 24524646 versión en línea No I8 Diciembre de 2020 
de nuestros conceptos a un plano superior que nos permita proponer una definición de Dios nos dice: "Lo máximo y lo mínimo, tal como se los considera en este libro son vocablos trascendentes, de significación absoluta, de modo que abracen todo en su simplicidad absoluta ${ }^{36}$.

Notemos especialmente la condición de absolutos de tales vocablos, es decir, que no están ligados a ningún otro ni tampoco hay otro que se le oponga, de modo que se excluya en virtud de su simplicidad toda composición. Tal es, en conclusión, el estatuto cognoscitivo que impone la misma realidad de Dios para el hombre.

A partir de estos presupuestos emprende Nicolás la valoración de la tradición catafática y apofática cristiana como asimismo analiza el lenguaje de los paganos acerca de Dios. A ello dedica los tres capítulos finales del libro I de Acerca de la docta ignorancia ${ }^{37}$. Nos dice en primer lugar: "Todos los nombres son impuestos a partir de una cierta particularidad de la razón, por medio de la cual se establece la distinción de uno respecto de otro" ${ }^{38}$. La irrenunciable función de la razón es valerse de su capacidad de distinguir y diferenciar pues sólo de este modo podrá denominar, es decir, mostrar algo en cuanto distinto de otro. Pero éste no es el caso aplicable a Dios, a quien nada se opone y en quien todo es uno. "Dios en su simplicidad complica la universalidad de las cosas", pero inmediatamente advierte: "La unidad no es un nombre de Dios a la manera como nosotros o bien nombramos o bien entendemos la unidad, porque así como Dios está por sobre todo intelecto, de la misma manera, a fortiori, está sobre todo nombre" 39 y explica el motivo de ello: "puesto que la razón no puede ir más allá de los contradictorios, de aquí que no hay nombre al que no se oponga otro de acuerdo con el movimiento de la razón".

La paradoja constante que Nicolás enfrenta plantea, por una parte, la limitación intrínseca de todo principio racional, pero por otro la exigencia metafísica de una realidad no sometida a las distinciones de la razón exige poder ser expresada de alguna manera. ¿Invalida con ello

36 NICOLÁS DE CUSA, De doc. ign., n. I2.

37 Dejamos de lado todos los capítulos que se esfuerzan por brindar con la ayuda de las analogías geométricas de la línea y de la esfera un concepto acerca de Dios, como asimismo las exposiciones que se refieren a su vida trinitaria: capítulos VI a XXIII Aquí consideraremos solamente los capítulos XXIV: "Acerca del nombre de Dios y de la teología afirmativa", el cap. XXV: "Los gentiles nombran a Dios de varias maneras con referencia a las criaturas"; cap. XXVI: "Acerca de la teología negativa".

38 NICOLÁS DE CUSA, De doc. ign., n. 74 .

39 NICOLÁS DE CUSA, De doc. ign., n. 76. 
cualquier afirmación que pretenda aplicarse a Dios? Solo una cuidadosa y prolija consideración permite salvar el escollo. Así lo expresa: "La unidad no conviene a Dios sino sólo aquella unidad a la cual no se opone ni la alteridad, ni la pluralidad, ni la multitud" $4^{\circ}$. Es decir, se trata ciertamente de una afirmación, pero enunciada no como contrapartida de la negación sino como plenitud sin opuestos. Sólo así podrá decirse de Dios: “aunque unidad parezca más próximo al nombre de lo máximo, todavía dista infinitamente del verdadero nombre de lo máximo que es lo máximo mismo"41 concluye aclarando el preciso sentido de su propuesta la cual confirma invocando la fórmula que ha encontrado en la obra del mismo Pseudo Dionisio: "las afirmaciones son inconsistentes"42, por cuanto, precisamente la "consistencia" de las afirmaciones proviene de su diferenciación respecto de lo que se le opone, pero lo máximo, según Nicolás, carece de oposición. De donde, concluye: "los nombres afirmativos, si le convienen (a lo máximo) no le convienen sino con referencia a las creaturas" 43 y lo que ellos ponen de manifiesto es, nos dice, "la potencia infinita respecto de las creaturas" 44 , es decir, en cuanto que expresan lo que Dios desde la eternidad pudo crear ${ }^{45}$. Con todo las limitaciones que Nicolás establece para las afirmaciones acerca de Dios no significan desconocer el valor que han tenido los distintos nombres que se han dicho de Dios a través de la historia.

"Los paganos nombraban a Dios según diversos modos de ver a las creaturas. Lo llamaban Júpiter, ciertamente a causa de su admirable piedad, lo llamaban Marte por sus virtudes guerreras, Mercurio por su prudencia para el consejo, etc." ${ }^{46}$.

La pluralidad y diversidad de tales nombres no es sino una "explicación", en el preciso sentido cusano de despliegue de aquello que proviene de su fuente la cual reúne o "complica" en sí todo. Por lo mismo: "los nombres que explican podrían ser muchos pero jamás tantos y tan grandes sin que no pueda haber más, cada uno de los cuales se relaciona

40 NICOLÁS DE CUSA, De doc. ign., n. 76.

4I NICOLÁS DE CUSA, De doc. ign., n. 77.

42 NICOLÁS DE CUSA, De doc. ign., n. 72; PSEUDO-DIONYSIUS AREOPAGITA, De Coelesti Hierarchia II, 3 PG. 3, I4I A: "Affirmationes sunt incompactae".

43 NICOLÁS DE CUSA, De doc. ign., n. 79.

44 NICOLÁS DE CUSA, De doc. ign., n. 79.

45 A propósito de estas consideraciones inserta Nicolás (n. 80 y 8I) su reflexión acerca del carácter de los nombres trinitarios que si bien se aplican a Dios sin embargo provienen del ámbito de las creaturas. No ingresaremos en esta cuestión teológicamente interesante.

46 NICOLÁS DE CUSA, De doc. ign., n. 83. 
al propio e inefable como lo finito a lo infinito" 47 .

Más en esta evolución de la expresión religiosa de los pueblos detecta Nicolás un desvío posible. En efecto, según los testimonios históricos, nos dice:

“...algunos daban culto en aquellas cosas en las que encontraban una explicación de la divinidad, tomando lo que es conocido sensiblemente como una guía hacia la causa y el principio. Y en este último caso han sido seducidos los hombres simples del pueblo quienes no utilizaron la explicación como imagen sino como verdad. A partir de esto fue introducida en el vulgo la idolatría" ${ }^{48}$.

Al no saber reconocer la inefabilidad de Dios, el peligro de divinizar cualquiera de las imágenes con que los hombres denominan a Dios erige como divinidad, lo que tan solo es un signo de Dios.

El último capítulo de este libro primero Acerca de la docta ignorancia está dedicado a la teología negativa proponiendo, de esta manera, cuál haya sido el alcance definitivo de su investigación impulsado por el apetito de saber con el cual la inició.

No significa esto, en primer lugar, que Nicolás pretenda con ello reemplazar la teología afirmativa por la negativa porque "toda religión en su culto asciende necesariamente, por medio de la teología afirmativa adorando a Dios"49. Pero, dado el peligro de la idolatría al que se refirió anteriormente "la teología de la negación es tan necesaria respecto de la otra teología de la afirmación que sin ella Dios no recibiría culto como Dios infinito, sino más bien como creatura. Y una tal religión -concluye Nicolás- es idolatría que confiere a una imagen aquello que tan solo corresponde a la verdad" ${ }_{50}$.

Nuevamente es el ejemplo "del gran Dionisio" el que ha mostrado a Nicolás este camino de la prevalencia de la teología negativa. "Y conforme a la teología negativa no se encuentra en Dios otra cosa sino la infinitud" ${ }^{51}$. Y de ello concluye:

47 NICOLÁS DE CUSA, De doc. ign., n. 84. 48 NICOLÁS DE CUSA, De doc. ign., n. 84. 49 NICOLÁS DE CUSA, De doc. ign., n. 86.

50 Más adelante veremos cómo esta relevancia que Nicolás otorga a la negación lo conduce a proponer la primacía de la negación sobre la afirmación.

5I NICOLÁS DE CUSA, De doc. ign., n. 88. 
"Por lo cual, de acuerdo con ella, Dios no es cognoscible ni en este tiempo ni en el futuro por cuanto toda creatura es tiniebla desde este punto de vista: ella no puede comprender la luz infinita, sino que Dios es el único que se conoce a sí mismo"52.

Y concluyendo la parábola que condujo este itinerario en la búsqueda de un posible acceso a la cognoscibilidad de Dios enuncia: "la precisión de la verdad brilla incomprensiblemente en las tinieblas de nuestra ignorancia. Y esta es aquella docta ignorancia que hemos investigado" 53 .

\section{3) La tradición escolástica acerca del principio}

La novedad de la propuesta cusana se nos presentará más explícitamente si la contraponemos con la tradición metafísica que tanto Alberto Magno, como Tomás de Aquino elaboraron a partir de su descubrimiento y asimilación del pensamiento del Estagirita expuesto previamente en los textos y comentarios de los filósofos árabes, a ellos se agregarán luego las traducciones latinas del original griego preparadas por G. de Moerbeke.

Comenzamos, entonces, nuestra exposición a partir de Alberto Magno $^{54}$. De su vastísima obra escogemos un escrito que ha merecido especial atención por parte de los estudiosos el De causis et processu universitatis a prima causa55. La obra data de los años I264-I267 y está dividida en dos libros. El primero presenta un completo tratado de teología racional. El segundo propone un comentario al Liber de causis, considerado por Alberto como obra fundamentalmente aristotélica ${ }^{56}$.

En el primer libro se propone previamente una crítica a las diversas opiniones filosóficas respecto del primer principio. Menciona a

52 NICOLÁS DE CUSA, De doc. ign., n. 88.

53 NICOLÁS DE CUSA, De doc. ign., n. 89.

54 Para todo este desarrollo remitimos a nuestro estudio: J. M. MACHETTA, "Die Präsenz Alberts des Grossen im Denken des Nikolaus von Kues" en Nikolaus von Kues in der geschichte des Platonismus, K. REINHARDT, H. SCHWAETZER, Regensburg, 2007, pp. I35-I66.

55 A. MAGNUS, De causis et processu universitatis a prima causa en: Opera Omnia, ed. Coloniensis tomus XVII, pars II,edidit Winfridus Fauser S.J., Monasterii Wersfalorum in Aedibus Aschendorf 1993.

$56 \mathrm{El}$ segundo libro de este tratado de A. Magno desarrolla un comentario al Liber de Causis el cual es considerado por A. Magno como resultado de una recopilación realizada por un judío de nombre David acerca de una carta sobre el principio del universo atribuida a Aristóteles a la que se incorporaron los comentarios de Avicena y de Alfarabi. En base a estos antecedentes Alberto consideró dicho libro como el culmen de la filosofía primera del Estagirita. Para toda esta cuestión ver la minuciosa descripción y la mención de las fuentes bibliográficas en A. DE LIBERA, Albert le Grand et la Philosophie, Vrin: Paris, I990, ver especialmente p.55 ss. 
Epicuro, a los platónicos, a los estoicos, a Avicebron. Aborda luego en un desarrollo sistemático, y utilizando como fuente principal la Metafísica de Algazel, el tema acerca del primer principio. A ello dedica varios capítulos. Así, por ejemplo, encabeza definidamente el tercer capítulo proponiendo: "quod necesse est esse unum primum principium omnium creaturarum" 57 .

Apelando al libro octavo de la Física aristotélica, nos dice:

"De modo similar demuestra Aristóteles en el libro VIII de la Física que si en el género de los que se mueven y de los motores se encuentra lo que mueve a lo movido, es necesario que se encuentre lo solamente movente y lo solamente movido. Y lo tan solo movente será lo primero y lo tan solo movido será lo último".

\section{Y concluye:}

"Por lo tanto es evidente que en cualquier género de causas es necesario que un único principio primero sea el principio y es necesario que lo último sea aquello en lo cual culmina la potencia del principio primero de modo tal que más allá del principio nada se expanda de su potencia" ${ }^{\prime 8}$. nos dice:

En seguida precisa en qué sentido se lo llama primer principio59;

“...puesto que el principio primero se dice aquello que nada es antes de él y después de él que haya algo, no es dicho principio primero antes del cual nada hay de modo tal que nada sea lo anterior a ello mismo y que ello mismo haya procedido de la nada", ${ }^{60}$

y se debe a que tal principio "no tiene el ser sino por sí mismo y

57 A. MAGNUS, De causis et processu universitatis, L.I Tract. I cap.7 p. I4ss.

58 A. MAGNUS, De causis et processu universitatis, L. I Tract. I cap.7 p.I5: "Similiter probat Aristoteles in VIII Physc. Quod si in genere moventium et motorum invenitur movens motum, necesse est inveniri movens tantum et motum tantum. Et movens tantum erit primum, motum tantum ultimum" Y como conclusión del desarrollo de estas premisas afirma, ibid.:"Patet igitur, quod in quolibet genere causarum necesse est unum primum esse principium et necesse est ultimum esse in quo finitur virtus principii primi ita quod ultra illud nihil extenditur de virtute eius".

59 Es precisamente el título del cap. 8 en A. MAGNUS, De causis et processu universitatis, p. I6: "Qualiter primum principium dicatur primum principium".

6o A. MAGNUS, De causis et processu universitatis, p. I6: "Cum autem primum dicatur ante quod nihil et post quod aliquid, non dicitur primum principium ante quod nihil ita quod nihil sit ante ipsum et ipsum ex nihilo processerit". 
que su ser no depende de otro" ${ }^{61}$. Invoca a su vez el lenguaje de Boecio, a quien cita:

"Y esto es lo que Boecio afirma en el libro Acerca de las semanas: Lo que es puede tener algo además de aquello que ello mismo es. El ser, empero, nada tiene añadido por lo cual conviene que su ser tenga su raíz en sí mismo y que para sí sea lo mismo el ser y lo que es". ${ }^{62}$

En síntesis, el primer principio es tal porque es fuente y plenitud de ser: "a se habet esse" enunció, configurando una fórmula que se consagrará en la escolástica. En contrapartida lo propio de las creaturas, por cuanto son causadas, es que se distinga en ellas aquello que son (id quod est) y el ser (est). Por ello luego de desarrollar una larga paráfrasis de las doce propiedades del ser propuestas por Algazel concluye:

“...de todo esto resulta que todo cuanto es, en la totalidad del mundo, es por aquel que es ser necesario y que él mismo de ninguna manera es o puede ser por otro, ni respecto del ser ni respecto de aquello que es ni respecto del intelecto"63.

Los textos aducidos nos permiten concluir que la metafísica de Alberto Magno se asienta en la primacía absoluta del ser, a la cual se atribuye el carácter de principio primero y, consiguientemente, en la exclusión de cualquier hipótesis que, apelando a la infinitud de causas intermedias o bien predicando la identidad de la causa con lo causado, pretenda ignorar la necesidad absoluta de la causa primera.

Siguiendo la línea elegida por su maestro, Tomás se esfuerza en demostrar todas las implicancias que tal metafísica involucra. Si de los textos de Alberto Magno citados se resalta la consideración del primer principio en cuanto fuente de todo ser, es decir, se ubican claramente en el nivel ontológico del ser del que todo procede, cuando abordamos los textos de Santo Tomás nos encontramos explícitamente no sólo con

6I A. MAGNUS, De causis et processu universitatis, p. I6: "Et ex hoc sequitur quod esse non habet nisi a seipso et quod esse eius non pendeat ex alio".

62 A. MAGNUS, De Hebd. Pl. 64,I3IIc, p. I7: "Et hoc est quod dicit Boetyhius in libro de hebdomadibus quod est habere aliquid potest praeter id quod ipsum est. Esse vero nihil habet admixtum. Propter quod oportet quod esse suum radicatum sit in seipso et sit sibi idem esse et quod est".

63 A. MAGNUS, Lib.I Tract. I, c.Io p.23: "Ex omnibus his relinquitur quod omnia quae sunt in universitate mundi sint ab eo quod necesse est esse et quod ipsum nullo modo sit vel posit esse $\mathrm{ab}$ alio neque secundum esse neque secundum id quod est neque secundum intellectum et quod omnia alia eo quod in unoquoque eorum aliud sit esse et id quod est, necesse est esse ab illo et quod ipsum est fons et origo omnium quae sunt". 
la misma línea de pensamiento de su maestro, sino que advertimos un matiz particularmente rico e importante que, a nuestro entender, complementa el texto albertino.

Tomás insiste particularmente en la consideración de lo que podríamos calificar como nivel lógico para el tratamiento del principio primero, es decir, el nivel que relaciona el ejercicio intelectual posible del conocimiento en su aplicación al conocimiento de la realidad. Tomás ha recorrido en su exposición acerca de la metafísica aristotélica larga y minuciosamente el significado y el alcance del primer principio, mostrando la profunda armonía entre el pensar y el ser ${ }^{64}$. Toda la obra tomista testimonia fielmente la aceptación del enfoque aristotélico y al mismo recurre cada vez que lo considera necesario. Citemos, a modo de ejemplo, un texto tomado de la Summa theologica. Se trata de los principios que son por sí mismos conocidos en el orden de la ley natural. Para explicar esto apela a la doctrina inobjetable que expresa, en el orden especulativo, lo mismo que puede afirmarse para el orden práctico de la ley natural:

“...pues aquello que en primer lugar cae en la aprehensión de todos es el ente, cuya intelección se incluye en todo cuanto uno aprehende. Y por ello el primer principio indemostrable es que no se da el afirmar y el negar al mismo tiempo, lo cual está fundado sobre la razón del ente y del no-ente. Y sobre este principio está fundado todo lo demás como se dice en el libro IV de la Metafísica". ${ }^{5}$

En consecuencia, la certeza tanto de la afirmación como de la negación se apoya en este principio evidente por sí y por ello indemostrable, el cual no hace sino poner en evidencia la 'razón' de ente y no-ente. Ello es así porque como Tomás explícitamente expresa:

“...el entendimiento naturalmente conoce el ente y aquello que de por sí es del ente en cuanto tal, y en tal conocimiento se fundamenta el conocimiento

64 TH. AQUINAS, Expositio in duodecim Libros Metaphysicorum Aristotelis, ed.M. R.CATHALA, R. SPIAZZI, Marietti: Torino, I964. El tema al que aludimos se halla especialmente expuesto en el comentario al Libro IV: "De iis quórum consideratio pertinet ad hanc scientiam: nempe de ente , de uno et multis, de eodem et diverso, de primis principiis demonstrationis", particularmente Lect. IV y V p. I63 a I68 de la edición citada.

65 TH. AQUINAS; S. Theol. I-II, q.94 art.2 c.: "Respondeo dicendum quod sicut supra dictum est praecepta legis naturalis hoc modo se habent ad rationem practicam , sicut principia prima demonstrationum se habent ad rationem speculativam: utraque enim sunt quaedam principia per se nota....Nam illud quod primo cadit in aprehensione intellectus est ens, cuius intellectus includitur in omnibus quaecumque quis aprehendit. Et ideo primum principium indemonstrabile est quod non est simul affirmare et negare quod fundatur super rationem entis et non entis et super hoc principium omnia alia fundantur ut dicitur in IV Metaphysicorum". 
de los principios. Como, por ejemplo, que no se da el afirmar y el negar simultáneamente" ${ }^{16}$.

Notemos de paso como en estos textos no hay lugar para la desvinculación entre los principios en cuanto enunciados por el entendimiento, afirmación y negación, y el ente que es el sujeto (subiectum) de la filosofía primera como lo describe abundantemente en su comentario al libro IV de la Metafísica ${ }^{67}$.

Por último, muy explícitamente propone Santo Tomás cómo se accede al primer principio:

“...siendo doble la operación del intelecto, una por la cual conoce aquello que es, la cual operación es llamada inteligencia de lo indivisible, la otra con la cual se compone y divide, en ambas hay algo primero. En la primera operación hay algo primero que recae en la concepción del intelecto, es decir, aquello que llamo ente, ni hay cosa alguna que pueda ser concebida por la mente con esta operación a no ser que se entienda el ente. Y porque este principio, imposible es ser y no ser simultáneamente, depende de la intelección del ente; por ello este principio es naturalmente primero en la segunda operación del entendimiento, es decir, en cuanto compone y divide" ${ }^{168}$.

Los textos citados nos permiten, en consecuencia reconocer que tanto para Alberto Magno como para Tomás la especulación procede de la aprehensión del ser y que dicha aprehensión es indubitable porque está fundada en la primacía e indemostrabilidad del principio de nocontradicción.

Nos interesa destacar, particularmente, dos consecuencias que estos autores reconocen y proclaman a partir de estos principios. La

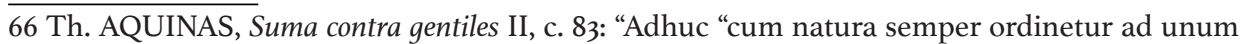
...naturaliter igitur intellectus noster cognoscit ens et ea quae sunt per se entis in quantum huiusmodi, in qua cognitione fundatur primorum principiorum notitia ut non esse simul affirmare et negare".

67 Th. AQUINAS, In Met, L.IV lect. I n. 533. p. I5I: "Ostendit quod ista scientia habet ens pro subjecto,tali ratione. Omne principium est per se principium et causa alicuius naturae, sed nos quaerimus prima rerum principia et altissimas causas".

68 Th. AQUINAS, In Met. L.IV lect.VI n. 605, p. I67: "Ad huius autem evidentiam sciendum est quod cum duplex sit operatio intellectus:una qua cognoscit quod quid est, quae vocatur indivisibilium intelligentia; alia qua componit et dividit; in utroque est aliquod primum: in prima quidem operatione est aliquid primum quod cadit in conceptione intellectus scilicet hoc quod dico ens; nec aliquid hac operatione potest mente concipere nisi intelligatur ens.. Et quia hoc principium, impossibile est esse et non esse simu, dependet ex intellectu entis, sicut hoc principium omne totum est maius sua parte ex intellectu totius et parties; ideo hoc etiam principium est naturaliter primum in secunda operatione intellectus, scilicet componentis et dividentis". 
primera se refiere al tema de la analogía del ser. La segunda al axioma de que toda negación se funda en una afirmación previa.

Respecto de la doctrina acerca de la analogía del ser ésta se funda en la vigencia del principio de causalidad según el cual la entidad del efecto es de alguna manera en la causa porque de ella proviene todo su ser. La analogía, precisamente, destaca la gradualidad entitativa que proviene del principio y que por ello mismo, a partir de la entidad de lo causado, permite pensar en la entidad del principio. Es verdad, sin embargo, que la definición y aplicación concreta de la doctrina de la analogía no es la misma en ambos autores. Si Tomás insiste en la relación efecto-causa para asegurar el vínculo entre lo analogado y su principio ${ }^{69}$, Alberto expone lo que denomina analogia univoca, -lo que en primera instancia podría tomarse como una contradictio in adiecto-, sin embargo, ello será ampliamente aclarado y explicado por su autor ${ }^{70}$. De todas formas, para ambos autores, el vínculo de efecto-causa se expresa apelando a la analogía.

La otra consecuencia enuncia el axioma que hemos encontrado en los textos citados acerca de la prevalencia de la afirmación sobre la negación y acerca de la dependencia de toda negación con respecto a la afirmación. Para ambos autores, como hemos visto, dicho enunciado proviene de Aristóteles mismo. Tomás lo repite frecuentemente $\mathrm{y}$, caso notable porque tiene que ver con su exégesis del Pseudo Dionisio, relativiza la afirmación dionisiana acerca de las afirmaciones incongruentes contestando que "el intelecto de la negación siempre se funda en alguna afirmación" 71 , o como Alberto proclama: "todo lo negativo tiene ante sí lo afirmativo, que es su causa"72.

Asimismo, como muestra del vehemente rechazo que generó la obra cusana Acerca de la docta ignorancia podemos mencionar el opúsculo de J. Wenck, profesor de teología en la Universidad de Heidelberg y contemporáneo de Nicolás de Cusa. Su opúsculo De ignota literatura despliega una crítica vehemente para prevenir: "el peligroso veneno del

69 Entre los innumerables textos acerca de este tema remitimos a los que Tomás desarrolla en S.Theol. I, q.I3 y De Veritate. Q. 2.

70 El tema ha sido ampliamente expuesto y analizado en A. de LIBERA, Albert le Grand, p. 8o -II6. 7I Es la manera cómo Tomas contesta a la objeción esgrimida desde la sentencia del Pseudo Dionisio, De Pt. q.5 a.5: "et praeterea intellectus negationis semper fundatur in aliqua affirmnatione".

72 A. MAGNUS, De causis, Lib.I Tract. I c. 8 p. I6: "Omnis enim negativa ante se habet affirmativam, quae causa negationis est, ut cum dico homo non est asinus, causa hius est quia homo est homo". 
error cusano que desprecia toda la doctrina de Aristóteles. ${ }^{73}$

\section{4) La primacía de la negación en los escritos posteriores del Cusano}

Si bien las doctrinas sobre la docta ignorancia y la coincidencia de los opuestos resultaron un original y a la vez desafiante propuesta teológicofilosófica que se contraponía a la tradición escolástica que hemos descrito, las reflexiones del Cusano no se privaron de analizar críticamente la propia producción para avanzar desde allí hacia la primacía de la negación sobre la afirmación. Por otra parte, es este -según nuestro entender- un aspecto de la doctrina cusana que no ha tenido por parte de los estudiosos la relevancia que merece. En consecuencia, recorreremos, aunque sea sintéticamente las nuevas expresiones acuñadas por Nicolás en su obra posterior.

En su segundo escrito especulativo, el De Coniecturis $^{74}$ (I440-I444), al cual remitiera desde su obra "Acerca de la docta ignorancia", Nicolás se propone replantear el alcance de su propio lenguaje y para ello corrige su anterior formulación a fin de señalar el verdadero alcance de su propuesta:

“...en lo expuesto en la docta ignorancia recuerdo que frecuentemente he hablado de Dios de modo intelectual a través de la reunión de los contradictorios en la simple unidad. Pero en lo que ahora propuse he explicado lo dicho de modo divino: es más simple y sin proporción la negación de los opuestos formulada disyuntiva y copulativamente que su reunión"75.

¿A qué alude esta corrección de su lenguaje? El capítulo

73 Cf. J. Wenck, De ignota litteratura. Texte inédit et ëtude par E. Vansteenberghe, Münster, I9Io, p. 21y 29: "O quantum spargitur hic venennum erroris et perfidie corolario isto destruente omnem processum scientificum ac omnem consequentiam, pariter et tollenter omnem consequentiam, pariter et legen contradictionem et per consequens totam doctrinam Aristotelis". Por su parte Nicolás de Cusa respondió a estas acusaciones en su Apologia doctae ignorantiae. Edidit R. Klibansky (Lipsiae MCMXXXII).

74 Nicolai de Cusa De Coniecturis, ediderunt J.Koch et C.Bormann J.G. Senger comité, Hamburgi, In Aedibus felicis Meiner MCMLXXII (h III)

75 NICOLÁS DE CUSA, De Coni. I, (h. III, n. 24): "Nam in ante expositis De docta ignorantia memor sum de deo me intellectualliter saepe locutum per contradictoriorum copulationem in úntate simplici. Iam autem in proxime praemissis divinaliter intentum explicavi. Improportionabiliter simplicior est negatio oppositorum disiunctive ac copulative quam eorum copulatio." En todos los casos se citará la edición crítica de las obras de Nicolás de Cusa con excepción de Acerca de lo no-otro o de la definición que todo lo define. Nuevo texto crítico original (edición bilingüe) Buenos Aires, 2008. La traducción de los textos latinos es responsabilidad nuestra. Para una explicación adecuada de esta precisión cusana remitimos al excelente estudio de H.G. Senger, Die Sprache der Metaphysik, (p.74 - IOI) en Nikolaus von Kues, Einführung in sein philosophisches Denken, herausgegeben von Klaus Jacobi (Karl Albert Freiburg/München 1979). 
inmediatamente anterior se refirió a la primera unidad, es decir Dios. Al evaluar el lenguaje conjetural posible para denominarla dice:

"ahora bien, porque se piensa que toda afirmación se opone a la negación, te das cuenta que aquello dicho antes no puede ser muy preciso por esto: porque lo primero infinitamente anticipa a la oposición; a lo infinito nada le conviene que no sea lo infinito mismo. En consecuencia, para referirse a lo infinito no hay una conjetura muy verdadera que admita la afirmación a la cual se opone la negación o que prefiera la afirmación a la negación como si fuera más verdadera... Por lo tanto, se da un concepto de la verdad más desvinculado de toda oposición, el cual rechaza ambos opuestos, sea disyuntivamente y, a la vez, copulativamente" ${ }^{\prime 6}$.

De esta manera introduce Nicolás una doble acepción de la negación. Aquella que simplemente se contrapone a la afirmación, y que queda entonces encerrada en los límites de las determinaciones a que se refiere, y aquella que es por sobre la disyunción o la reunión de los opuestos. La primera acepción de negación, a la cual se refiere en la primera parte del texto citado, se anticipa, entonces, al infinito, a toda oposición; esto supone que para Nicolás hay un nivel de negación que se ubica en un plano infinitamente más alto, es decir sin medición posible al de los enunciados propios de la racionalidad, o sea aquellos en que la contraposición desempeñe un rol decisivo. Dicho en otras palabras estamos ante lo que él denominó nivel "divinal" y que contrapone a lo que denomina "intelectual", en el cual se propuso originalmente la coincidencia de los opuestos. De este modo reformula su posición en coherencia con su concepto de lo absoluto o desvinculado.

Pasemos, ahora, a su obra De Beryllo ${ }^{77}$, Nicolás se propone -accediendo a las repetidas instancias de sus amigos los monjes de Tegernsee ${ }^{78}$ - escribir acerca de la lente que permitirá visualizar la evidencia de la superación de la contradicción. En efecto, afirma, "si el beryllo intelectual, que posee la forma máxima y a la vez mínima, se

\footnotetext{
76 De coni I c. 5 (h III no 2I p. 26ss.): "Quoniam autem omnis affirmatio negationi adversari creditur, haec iam dicta responsa praecisissima esse non posse ex hoc advertis quod primum per infinitum omnem praeit oppositionem, cui nihil convenire potest non ipsum. Non est igitur coniectura de ipso verissima quae admittit affirmationem cui opponitur negatio, aut quae negationem quasi veriorem affirmationi praefert... Absolutior igitur veritatis existit conceptus, qui ambo abicit opposita, disiunctive simul et copulative"

77 La obra De Beryllo (I458), marca a nuestro entender, juntamente con el opúsculo Tu quis es, De Principio (I459), un punto de inflexión en el desarrollo o mejor en la maduración del pensamiento cusano. Acerca del De Beryllo Kurt Flasch en su obra Nicolaus Cusanus, Beck:München, 200I, presenta un original abordaje que, por otra parte no ha estado extento de críticas y reparos.

78 Remitimos al abundante intercambio epistolar entre Nicolás y los monjes recopilado por E. VANSTEENBERGHE, Autour de la Docte Ignorance, Münster , 1915.
} 
adapta a los ojos del intelecto, por su intermedio se alcanza el principio indivisible de todo"79.

Y al tratar de arribar, a través de estas consideraciones, a una formulación intelectual lo más pura posible reconoce en el concepto de indivisibilidad el principio supremo: "la indivisibilidad es el principio previo a todo... y de acuerdo al concepto intelectual lo indivisible es el principio más formal y más preciso el cual no puede ser alcanzado sino negativamente"so.

Notemos la exigencia: sólo apelando a la negatividad se alcanza el principio. No se trata, por tanto, de afirmar la negación porque de ese modo se fundaría la negación en una afirmación, sino se trata de reconocer la necesidad de apelar a la modalidad de la negación -Nicolás lo dice adverbialmente: negative- en cuanto única posibilidad para acceder a lo propio de la indivisibilidad.

Por esto mismo no es forzada la crítica que Nicolás dirige en esta obra a Aristóteles al recriminarle no haber advertido que:

“...si al principio que llama privación lo hubiera entendido de tal manera que de por sí la privación sea el principio que pone la coincidencia de los contrarios y por eso está privado de la contrariedad de uno y otro, como precediendo a la dualidad que es necesaria en los contrarios, entonces hubiera visto correctamente. Ahora bien, el temor para confesar que los contrarios son simultáneamente en lo mismo lo privó a él de la verdad de aquel principio"8I.

Encontramos, en consecuencia, en este texto que no sólo se habla de principio sino que explícitamente tal principio no es sino por sobre toda oposición. Precede, entonces a la contradicción y por ello es denominado principio indivisible y no principio de contradicción, es decir, se trata de un principio no participado y que en sí no incluye

79 NICOLÁS DE CUSA, De Beryllo (h. XVI n. 3): "Intellectualibus oculis si intellectualis beryllus, qui formam habeat maximam pariter et minimam, adaptatur, per eius médium attingitur indivisibile principium omnium".

8o NICOLÂS DE CUSA, De Beryllo (h. XVI, n. 53): "Unde eo modo videtur secundum has intellectuales conceptiones quod indivisibilitas sit principium prius ómnibus...et secundum intellectualem conceptum indivisibile est formalius et praecisius principium, quod tamen non potest nisi negative attingi".

8I NICOLÁS DE CUSA, De Beryllo (h. XVI, n. 42): "Quod si Aristóteles principium quod nominat privationem sic intellexisset ut scilicet privatio sit principium ponens coincidentiam contrariorum et ideo privatum contrarietate utriusque tanquam dualittem quae in contrariis necesaria est, praecedens, tunc bene vidisset. Timor autem, ne contraria simul eidem inesse fateretur abstulit sibi veritatem illius principiit". 
la composición sino que es anterior a ella, - "previo" dice Nicolás-. El único posible acceso al principio por parte nuestra: es "negativamente" -negative-. De donde, sólo podemos referirnos al principio como a lo que no es pues si intentáramos expresarlo de modo positivo, es decir si pretendiéramos decir qué es, pondríamos en él una determinación y le asignaríamos en consecuencia un límite. Entender la privación "privatio" como principio ponente "ponens" no es enunciar una "contradictio in adjecto" sino valerse de la única formulación posible para no someter aquello que es por sobre nuestro entender y nuestro ser a los límites y determinaciones peculiares de nuestro entender y de nuestro ser. Con todo, la elaboración más explícita acerca del tema de la negación en cuanto principio la encontramos en el escrito de I459 "Tu quis es, De Principio"82.

Allí el Cusano, impactado por el pasaje del evangelio de San Juan, texto que lee según la versión de la Vulgata y que lo lleva a interpretar la perícopa como una autodefinición de Cristo en cuanto principio, se esfuerza en querer poner de relieve la plenitud y profundidad implicada en dicha significación ${ }^{83}$. Se vale para ello y es éste un dato sumamente importante para comprender la gestación de la filosofía cusana, de la coherencia que reconoce entre su propia doctrina y el comentario al Parménides de Proclo, obra que lee en la difundida traducción de Moerbeke. El mismo Nicolás ha enriquecido su propio manuscrito de esta traducción con clarificantes notas marginales. ${ }^{84}$

Nos valdremos para ello de lo que el mismo Nicolás propuso como resumen de su especulación ${ }^{85}$. Recuerda en primer lugar la

82 NICOLÁS DE CUSA, Tu quis es. De principio (h. X/II). Remitimos, asimismo, a la muy importante edición de la versión alemana: Über den Ürsprung, Deutsch mit Einführung von M. Feigl. Vorwort und Erläuterungen von J. KOCH, F.H. KERLE:, Heidelberg, 1967, como también la nueva edición bilingüe -latin.alemán -Neu übersetzt, eingeleitet und mit Anmerkungen herausgegeben von K. BORMANN F. Meiner: Hamburg 20oI. Para todo este parágrafo remitimos al estudio: J. M. MACHETTA, "La noción de Principio en Nicolás de Cusa a partir del comentario al Parménides de Proclo", en: A recepçâo de pensamento greco-romano, árabe e judaico pelo Occidente Medieval, L. A. DE BONI y R. HOFMEISTER PICH (organizadores), PUCRS: Porto Alegre, 2004, pp. 689704. Como advierte M. FEIGL en la Introducción citada cuando redacta este opúsculo Nicolás dispone solamente del texto del Comentario al Parménides.

83 NICOLÁS DE CUSA, De Princ.(h. X/2b n. I): "Propositum est pro excercitatione intellectus de principio dei dono quaedam tangere".

84 El texto crítico de la versión latina de Moerbeke juntamente con los marginales que Nicolás de Cusa insertara en su manuscrito ha sido publicado en la excelente edición de: Proclus Commentaire sur le Parménide de Platon. Traduction de Guillaume de Moerbeke. Tome I, Livres I à IV, Tome II, Livres V à VII. Appendix: Nicolai de Cusa Marginalia ad Textum Procli quae inveniuntur in cod. Cusano 186 et vaticano lat. 3074.(Leuven, University Press 1982/84). Asimismo la colección Cusanus Texte (CT, III.2 Proclus Latinus 2.2: Die Exzerpte und Randnoten des Nikolaus von Kues: Expositio in Parmenides Platonis, hrsg. Von K. BORMANN, Heidelberg 1986.

85 NICOLÁS DE CUSA, De Princ.(h X/2b nº34 p.47): "Resumendo itaque quae tacta sunt, 
exigencia de Proclo: "el principio ha de ser no-múltiple" ${ }^{86}$ y explica este enfoque negativo de esta manera: "así como antes de lo múltiple es lo no-múltiple, así también antes del ente lo no-ente y antes del intelecto el no-intelecto y en general antes de lo enunciable lo no-enunciable ${ }^{87}$. En consecuencia, fundándose en el antes que corresponde al principio concluye que ni en el orden del ser, ni en el orden del conocer, ni en el del decir podemos ubicarnos para tratar acerca del principio por cuanto el principio es antes de todo ello.

Es, por tanto, necesario tener en cuenta, nos dice, su no enunciabilidad -ineffabile, dice el texto latino- otra denominación negativa conforme a la cual piensa el principio más allá de toda afirmación y de toda negación. Pero notemos que precisamente con esto se propone destacar una condición peculiar e imprescindiblemente inherente a la negación toda vez que se refiere a la negación que implica una excelencia, porque se habla de negación que es superadora, es decir, que es más que todo cuanto pueda oponérsele desde la afirmación y es, por tanto, por sobre toda determinación implicada en la afirmación, como habrá de explicitar.

Sólo a partir de esta perspectiva podrá comprenderse y aceptarse la afirmación cusana que enuncia taxativamente: "la proposición negativa es por tanto principio de todas las afirmaciones" $"$. Advirtamos en primer lugar el uso del término "principio", cuyo significado en el texto alude siempre a lo que genera, es decir es origen de algo. En este sentido se refirió antes a los orígenes intradivinos y también es aplicable a lo creado en cuanto dependiente $u$ originado. Pero es importante advertir que aquí el enunciado propuesto subraya especialmente a la negación en cuanto fundamento de la afirmación y en este sentido no hace sino apelar a una fórmula usual de Proclo $^{89}$, que Nicolás propone

principium esse uniternum et ipsum aeternum manifestum dico hunc mundum ab uniterno principio id esse quod est"

86 NICOLÁS DE CUSA, De Princ. l.c. "Nec sunt multa principia, ut patuit. Non multa non potest nisi unum concipi, ante igitur hunc mundum et multa principium , quod est non multa".

87 NICOLÁS DE CUSA, De Princ. l.c. "Sicut igitur ante multa non multa, sic ante ens non ens et ante intellectum non intellectus et generaliter ante omne effabile ineffabile".

88 NICOLÁS DE CUSA, De Princ.Ic: "Negativa igitur principium omnium affirmationum". Traducimos el "negativa" como referido a la proposición negativa porque aquí se contrapone ésta a la afirmativa según el contexto inmediato. Más abajo dirá Nicolás: "affirmatio est melius in negatione, cum negatio - aquí emplea el sustantivo- sit eius principium”.

89 Citamos tan sólo dos textos de Proclo porque han sido expresamente remarcados por aclaraciones marginales de NICOLÁS DE CUSA, In Par. VI (Steel, o.c. p. 379 1.37 ss.) "Non ergo multa le unum, sed causa multorum. Sic enim non multa, ut le non multa sit generativum multorum. Sed haec quidem de abnegatione secundum communem conceptum, ut dictum est sumpta." y el comentario marginal cusano resalta: "Unum causa multorum, quoniam non multa, 
de esta manera: "el principio es nada de lo principiado, más aun siendo todo lo causado más verdaderamente es en su causa que en sí mismo, la afirmación es en consecuencia en la negación, pues la negación es su principio" 90 . Recapitulando toda esta especulación acerca de la negación resume Nicolás su pensamiento de esta manera:

"Lo no múltiple, por lo tanto, principio de todo, complica todo, así como se dice que la proposición negativa es generante de la afirmación, es decir, así como el no ser de tal manera dice el no ser, de modo que sea significado por el ser, pero el ser mejor ${ }^{91}$

Notemos entonces que si bien Nicolás siempre respetó y reconoció el vínculo entre lo causado y la causa, ello lo realiza no a la manera de la tradición escolástica de la que dábamos cuenta antes. En efecto, para tal tradición a partir del vínculo causal se cuenta con el legítimo, y en su planteo único fundamento por el que desde lo relativo y causado puedan predicarse notas atribuibles a lo absoluto e incausado. En tal caso la distancia de lo finito respecto de lo infinito se podrá salvar únicamente valiéndose del puente que establece la analogía la cual lleva a su grado superlativo la afirmación.

Es precisamente este recurso a la afirmación lo que Nicolás cuestiona y descarta. Porque la verdad del principio es por sobre la verdad de lo principiado consecuentemente la inefabilidad del principio impone la imposibilidad de decirlo recurriendo a la dialéctica de la afirmación y de la negación, fundada en el principio de contradicción. Por tanto, se trata de una negatividad que reconoce en el principio la superación de todas nuestras determinaciones.

Hay, por tanto, para Nicolás que en esto prolonga la línea

et negativa non multa est generativum multorum".(marginal 468 ; cf. Otros marginales $n^{\circ} 485,459$, 460). El segundo texto, In Parm. VI, STEEL, p.366 l.43 señala: "Sed si me oportet breviter dicere quod videtur, sicut le unum causa est totorum, sic et negationes causae affirmationum sunt." Y el marginal cusano comenta: " conclusio: sicut unum causa totorum, sic negationes cause affirmationum, et bene exponit et exemplum ponit sicut incorporea anima hábeas producit et inanimalis intellectus animam, sic unum inmultiplicatum multitudinem."

9o NICOLÁS DE CUSA, De Princ (h. X/IIb, n. 34): "Principium enim nihil est principiatorum. Sed cum omne causatum verius sit in sua causa quam in seipso, igitur affirmatio melius est in negatione cum negatio sit eius principium".

9I NICOLÁS DE CUSA, De Princ. (h. X/IIb, n. 34): "Non multa igitur omnium principium omnia complicat, sicut negativa praegnans dicitur affirmationis, scilicet ut non esse dicit siic non esse ut per esse significatur, sed melius esse". Este mismo argumento lo encontramos en el comentario de Proclo citado: In Parm VI, p. 4II, al que corresponde el marginal cusano n. 520: "abnegationes matres affirmationum" y también In Parm VI, p. 470 lin. 98 al que corresponde el marginal n. 585 "abnegatio generatio affirmationis". 
neoplatónica, una otra negatividad que no es regida por el principio de contradicción pero ello no significa proponer un vacío o la ausencia absoluta de entidad. Si se llega a esta formulación es porque sólo por la negación se puede y se debe preservar su necesaria excelencia. Un texto de Nicolás nos lo advierte al asegurar, en clara referencia a un pasaje de Proclo ${ }^{92}$, que:

“...no es el principio del ente de ninguna manera ente sino que es noente del modo dicho. Por cuanto siendo el principio por sobre todo lo opuesto y lo decible inefablemente lo veo al mismo anticipadamente máximo y mínimo puesto por sobre todo lo que puede decirse. Por lo cual, consecuentemente, todo lo que se afirme de tal ente de modo similar se niega respecto del principio". ${ }^{93}$

Concluyendo esta exposición nos referiremos a su obra "Directio speculantis sive de non aliud"94, una de las últimas de Nicolás (I462). Del abundante material que el texto nos ofrece acerca de este tema elegimos algunas referencias que proponen muy claramente lo que ha sido el sentido y la clarificación que para el mismo Cusano trajo consigo el descubrimiento de la docta ignorancia

No es entonces casual, que uno de los interlocutores, Fernando, representante del punto de vista aristotélico, muestre su perplejidad ante la innovación terminológica y sobre todo conceptual del "non aliud".

92 In Parm VI, o.c. p. 37I lin. 79ss.: " Quod autem neque unum existens cum aliis ab omnibus necessarium excidisse, et hoc est nullatenus ens. Quod autem rursum ante ens unum, non ens quidem est, non tamen et nichil. Unum enim ens impossibile ipsum dicere nichil. Non ens igitur ipsum dicamus et intelligamus eo quod in nobis simili; etenim in nobis inest aliquod semen illius non entis et sic exaltatum ipsum ab entibus dicimus solum ne ad interminabile delati lateamus...qualiter quidem congrue ad le unum negations, et quomodo abnegantut omnia ab ipso et quod omnis cognitio unius per negationem est, ex his palam". A lo que Nicolás al concluir el desarrollo añadirá este largo comentario marginal ( $\mathrm{n}^{\circ}$ 447): "quae negantur ab uno quod non multa quod neque totum neque partem habens, quod neque principium habet neque medium neque consumationem, quod nullum habet terminum, quod infiguratum, quod neque in alio est neque movetur neque idem movetur. Neque idem neque alterum, quod neque simile neue dissimile,. Quod neque aequale neque maius neque minus, quod neque senius neque iunius, quod generatione nequaquam participat tempore non participans, quod neque ipso esse participat, quod neque nominabile neque dicibile est, quod neque opinabile neque scibile est". 93 NICOLÁS DE CUSA, De Princ.(hX2b no 34 p. 47): "Non est principium entis nullatenus ens, sed non ens modo dicto...sed quia idem principium est supra omnia oposita et effabilia ineffabiliter, video ipsum ante maximum pariter et minimum omnibus quae dici possunt, suprapositum. Quare consequenter omnia quae de ente affirmantur, pariformiter de principio negantur modo praemisso", Cf. Asimismo Proclo In Parm VII (p.418) y marginal cusano n. 535; In Parm VII (o.c. p.470 lin. 9) y marginal cusano 585. In Parm. VI (o.c. p.373 lin.19) y marginal cusano 456.

94 Remitimos al nuevo texto crítico original (edición bilingüe) de NICOLÁS DE CUSA, "Acerca de lo no-otro o de la definición que todo define" Introducción J. MACHETTA y K. REINHARDT. Traducción J. M. MACHETTA. Preparación del texto crítico y notas complementarias C. D' AMICO, M. D' ASCENZO, A. EINSENKOPF, J. GONZÁLEZ RÍOS, Jorge M. MACHETTA, K. REINHARDT, C. RUSCONI, H. SCHWAETZER. Biblos: Buenos Aires, 2008. 
De ahí su planteo:

"Dado que todos llaman a Dios primer principio, parece que tú ciertamente, quieres que se lo signifique a él mismo por medio de lo no-otro. Pues conviene proclamar primero mismo aquello que no sólo a sí mismo se define sino también a todo." 95

\section{Nicolás expresa su conformidad:}

"Me has captado correctamente, Fernando, pues aunque al primer principio se atribuyen muchos nombres, ninguno de ellos puede ser adecuado a Él, siendo también principio de todos los nombres como también asimismo de las cosas. Y nada de lo principiado antecede a todo".

De esta manera Fernando quiere preservar la necesidad la afirmación, por lo cual una fórmula negativa, lo no-otro, no parece ser adecuada para proponer como fundamento de todo. Sin embargo, Nicolás insiste en su propuesta:

“...tampoco hasta ahora he podido constatar cualquier otro significado que dirija la vista humana más correctamente hacia lo primero. Pues todo lo significado que culmina en algo otro o bien en lo otro mismo de la misma manera cómo todo lo otro es por lo no-otro mismo, precisamente no dirigen hacia el principio"96.

\section{No obstante, insiste Fernando con su pregunta:}

"Acaso quieres decir que no-otro es afirmación o negación o algo de su género ${ }^{97}$. La contestación de Nicolás constituye toda una revelación: "De ninguna manera, sino antes de todas aquellas. Y esto es lo que por medio de la coincidencia de los opuestos busqué durante muchos años, como ponen de manifiesto los muchos libros que escribí sobre esta especulación"98.

95 NICOLÁS DE CUSA, De non aliud (h. XIII, c.2): "Cum cuncti primum principium Deum appellent,videris tu quidem ipsum per li non-aliud velle significari. Primum enim fateri oportet quod et se ipsum et omnia definit".

96 NICOLÁS DE CUSA, De non aliud, (h. XIII, cap. II n. 6): "Nic. "Bene me capis, Ferdinande. Nam etsi primo principio multa attribuantur nomina, quorum nullum ei adaequatum esse potest,cum sit etiam nominum omnium sicut et rerum principium et nihil principiati omnia antecedat".

97 NICOLÁS DE CUSA, De non aliud, (h. XIII, n.I2): "Visne dicere non aliud affirmationem esse vel negationem vel eius generis tale?"

98 NICOLÁS DE CUSA, De non aliud, (h. XIII. n I2): "Nequaquam, sed ante omnia talia, et istud est quod per oppositorum coincidentiam annis multis quaesivi, ut libelli multi, quos de hac speculatione conscripsi ostendunt". 
La confesión cusana nos revela no sólo el íntimo propósito que animó su investigación acerca de la coincidencia de los opuestos, sino que nos pone de manifiesto el resultado de este largo peregrinaje por el cual valiéndose de la docta ignorancia procuró alcanzar el conocimiento del principio primero. Más aún, Fernando pregunta: “¿No-otro pone o quita algo? A lo cual responde inmediatamente Nicolás: "Es visto antes de toda posible posición y también de toda supresión”. Fernando entonces concluye: "Por lo tanto tampoco es sustancia ni ente, ni uno, ni cualquier otra cosa". A lo cual Nicolás responde: "Y esto lo veo precisamente así". ${ }^{99}$

En conclusión podemos decir que la fuerza del paradójico lenguaje cusano reside en esto: Proponer lo negativo como fuente de lo afirmativo, con lo cual se revierte totalmente la perspectiva metafísica escolástica: no es la afirmación fundamento de la negación sino exactamente al revés: es la negación fundamento y fuente -praegans la llamó-. Negar no es anular sino reconocer, a la par que nuestro límite, la incomprensibilidad del principio. Y es por ello que éste es el único camino posible desde nuestro limitado modo de conocer para referirse a Dios, totalmente absoluto, a quien nada se opone.

El recorrido que hemos intentado a través de los textos cusanos nos ha permitido, creemos, dilucidar la profunda intuición y a la vez total coherencia de su pensamiento. Si la superación de nuestro modo conjetural de conocimiento nos conduce a través del camino de la docta ignorancia hacia la coincidencia de los opuestos, la propuesta de la prioridad de la negación sobre toda contraposición de la dupla afirmación-negación no sólo revela nuestra impotencia fundada en la desproporción de lo finito ante lo infinito, sino que esa misma impotencia pone en evidencia que la única forma de alcanzar dicha excelencia la cual se establece como principio de todo será reconocida desde la negación, o como lo expresa la clásica fórmula cusana: "fui conducido a esto: a que abrazara lo incomprensible incomprensiblemente en la docta ignorancia" ${ }^{100}$.

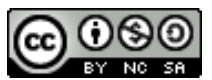

99 NICOLÁS DE CUSA, De non aliud, (h. XIII. n I2): "Neque igitur est substantia, neque ens , neque unum, neque aliud quodcumque. Nic. Sic equidem video".

Ioo NICOLÁS DE CUSA, Acerca de la docta ignorancia: Libro III Lo máximo absoluto y a la vez contracto. Introducción K. REINHARDT. Traducción y notas J. M. MACHETTA - E. LUDUEÑA. (Ed. Biblos: Buenos Aires, 2009). Carta del autor al Señor Cardenal Juliano. n. 263, p.I25. 
